\title{
Technique for microdissection and measurement in biopsies of human small intestine
}

\author{
ANNE FERGUSON, A. SUTHERLAND, T. T. MACDONALD, AND FRANCES ALLAN \\ From the Gastrointestinal Unit, University of Edinburgh and Western General Hospital, \\ Edinburgh EH4 $2 \mathrm{XU}, \mathrm{UK}$
}

SUMMARY A microdissection and measurement technique has been adapted for biopsy of human small intestine. Specimens fixed in alcohol and acetic acid are Schiff stained in bulk. Villi and crypts are then dissected out under a dissecting microscope, placed under a coverslip, examined, measured, and the number of mitoses in individual crypts counted. With this method specimens of normal small intestine have been found to have villi $500 \mu \mathrm{m}$ to $1100 \mu \mathrm{m}$ long and crypts $150 \mu \mathrm{m}$ to $300 \mu \mathrm{m}$. These values were double those obtained when measuring sections of the same specimens stained with haematoxylin and eosin. The mean number of mitoses per crypt in normal duodenum and jejunum ranged from 1 to 12 and most of the cells in mitosis were in prophase or telophase. This rapid, sensitive, and inexpensive technique complements the available methods of measuring small intestinal architecture.

To examine fully small intestinal architecture and epithelial cell kinetics information is needed on the shapes and sizes of villi and crypts, the number of crypts associated with each villus, and the number of crypt cells that enter mitosis in a given period (Clarke, 1970). Individual villi and crypts from intestinal tissue have been dissected and their shapes, sizes, and properties examined in animal work for more than a decade (Wimber and Lamerton, 1963; Clarke, 1970, 1973, 1974, 1975 a, b, 1976; Clarke et al., 1976; MacDonald and Ferguson, 1977). We have adapted the microdissection technique to the biopsy of human small intestine. This paper describes our modification of the technique and its application to the measurement of villi, crypts, and crypt mitotic counts in 90 specimens of morphologically normal tissue from the small intestine.

\section{Material and methods}

Tissue for biopsy of the proximal small intestine was obtained either by a Crosby capsule, under direct vision during upper gastrointestinal endoscopy, or at laparotomy in patients undergoing gastrojejunostomy or jejunoileal anastomosis.

Ninety specimens were examined. In all of them dissecting microscopy and conventional histological examination showed normal architecture. Out of the 90 specimens 74 were from the proximal jejunum and 16 from the second or third part of the duodenum.

Received for publication 23 May 1977
FIXATION

The specimen for examination was attached to a piece of flat aluminium foil, villi upwards, left for 60-90 seconds to adhere, and then immersed in Clark's fixative $(75 \%$ ethyl alcohol, $25 \%$ glacial acetic acid). After 3-24 hours at room temperature? the specimen was transferred to $75 \%$ ethyl alcohol in water and stored. Satisfactory preparations were obtained after storage for 6-8 weeks.

STAINING

Specimens up to $5 \times 5 \mathrm{~mm}$ were stained in bulk by the Feulgen reaction, as follows:

Transfer to $50 \%$ ethyl alcohol for 10 minutes; water for 10 minutes with three changes; molar hydrochloric acid at $60^{\circ} \mathrm{C}$ in a water bath for 6 minutes; water for 10 minutes with three changes; Schiff reagent at room temperature for 20 minutes; several rinses in water to remove excess Schiff reagent.

Specimens should be examined as soon as possible, and not more than 24 hours, after staining.

\section{MICRODISSECTION}

The specimen, in tap water, was examined with a dissecting microscope and, using fine forceps and a cataract knife, a number of strips $1.5-3 \mathrm{~mm}$ long and 1 villus thick were cut free. Four such strips were placed on a slide in a drop of $45 \%$ acetic acid (this clears the tissue slightly, making mitotic counts easier). A coverslip was applied gently and the preparation transferred to a light microscope. 
MEASUREMENTS OF CRYPTS AND VILLI

The shapes of crypts and villi were examined and, if appropriate, recorded by photography or by drawing with a camera lucida attachment (Fig. 1). Using an eyepiece graticule in a light microscope the height and width of villi and the depth of crypts were easily measured. Ten measurements of villus and crypt length were made in each specimen and the means calculated.

\section{MITOTIC COUNTS}

The preparation was then gently but firmly squashed to liberate the crypts from the lamina propria matrix and to flatten them out (Fig. 2). Excess acetic acid was removed from the edge of the coverslip and the number of mitotic figures in a range of crypts counted. The preparation could then be discarded or, if desired, preserved by ringing the coverslip with DePeX. All stages of mitosis were included in the mitotic counts, but when required the various stages (prophase, metaphase, anaphase, telophase) could be identified and counted separately (Fig. 3).

RELATIVE NUMBERS OF CRYPTS AND VILLI If the specimen was large enough a further portion of tissue $3 \mathrm{~mm} \times 3 \mathrm{~mm}$ was immersed in $45 \%$ acetic acid for 1-3 hours, thus partially decolorising the tissue. It was then transferred to a glass slide with the villi uppermost, $45 \%$ acetic acid was added, a coverslip applied, and the preparation flattened by very gentle pressure. With an eyepiece graticule calibrated for area and by focusing on two planes the number of villi and of crypts in a standard area could be counted and the number of crypts associated with each villus was then calculated.

MINOR TECHNICAL POINTS

(1) The method regularly produced good results when the tissue specimen was $2 \mathrm{~mm} \times 2 \mathrm{~mm}$ or larger, but smaller pieces could be difficult to dissect without causing considerable damage to the few villi and crypts present.

(2) Specimens of small intestine obtained at laparotomy contain much more connective tissue than a standard mucosal biopsy. The connective tissue is best peeled from the serosal surface after staining and before dissecting microscopy.

(3) When there is doubt about the origin of the sample of small bowel the presence or absence of Brunner's glands may identify it as duodenal or jejunal.

(4) In preparing the Schiff reagent care must be taken to use the correct grade of basic fuchsin. This stain is now supplied in two forms-one suitable for the Feulgen reaction and one for histological staining. The latter is completely unsuitable for the microdissection technique.

(5) The initial strip preparation of one row of villi can be preserved for several weeks for photography or demonstration by taking the strips from water through $10 \%, 20 \%$, and $30 \%$ glycerine $(10$ minutes in each) and then making the slide preparation in $30 \%$ glycerine. The coverslips may then be ringed with paraffin wax. Preserved preparations, however, are unsuitable for squashing and mitotic counts.

\section{Results}

SHAPES OF CRYPTS AND VILLI

In general the shapes of villi were as expected from dissecting microscopy examination. Finger-, leaf-, and spade-shaped villi and short ridges were identified. Comparison of villus shapes in the duodenum and jejunum showed that fewer specimens of duodenum had finger-shaped villi (Table 1). Most crypts were narrow and cylindrical although occasionally one was seen to be duplicating by fission (in animals a crypt divides by 'unzipping' from the base so that it looks like an inverted $\mathrm{Y}$ (Clarke, 1972; Cairnie and Millen, 1975)).

Table 1 Shapes of villi in biopsies of duodenum and jejunum

\begin{tabular}{|c|c|c|c|c|}
\hline \multirow[t]{2}{*}{$\begin{array}{l}\text { Site of } \\
\text { biopsy }\end{array}$} & \multirow[t]{2}{*}{$\begin{array}{l}\text { No. of } \\
\text { specimens }\end{array}$} & \multicolumn{3}{|c|}{$\begin{array}{l}\text { Per cent specimens with villus } \\
\text { shape: }\end{array}$} \\
\hline & & Finger & $\begin{array}{l}\text { Leaf and } \\
\text { spade }\end{array}$ & Ridge \\
\hline $\begin{array}{l}\text { Duodenum } \\
\text { Jejunum }\end{array}$ & $\begin{array}{l}16 \\
25\end{array}$ & $\begin{array}{l}25 \\
60\end{array}$ & $\begin{array}{l}50 \\
56\end{array}$ & $\begin{array}{l}69 \\
44\end{array}$ \\
\hline
\end{tabular}

RANGE OF CRYPT AND VILLUS LENGTHS

Examination of the lengths of more than 100 crypts and villi in each of two operative specimens showed that the values for crypt length and villus length were normally distributed (values gave straight lines when plotted on probability paper). Results for one of these, a biopsy of jejunum from an obese patient undergoing jejunoileal bypass, are shown in Fig. 4.

CRYPT AND VILLUS LENGTHS IN 'NORMAL' BIOPSIES

The villus and crypt lengths in 90 histologically normal specimens from duodenum or jejunum are shown in Fig. 5. In most specimens duodenal and jejunal crypts were between $150 \mu \mathrm{m}$ and $300 \mu \mathrm{m}$ long. Jejunal villi were $500 \mu \mathrm{m}$ to $1100 \mu \mathrm{m}$ long, while duodenal villi were slightly shorter. 


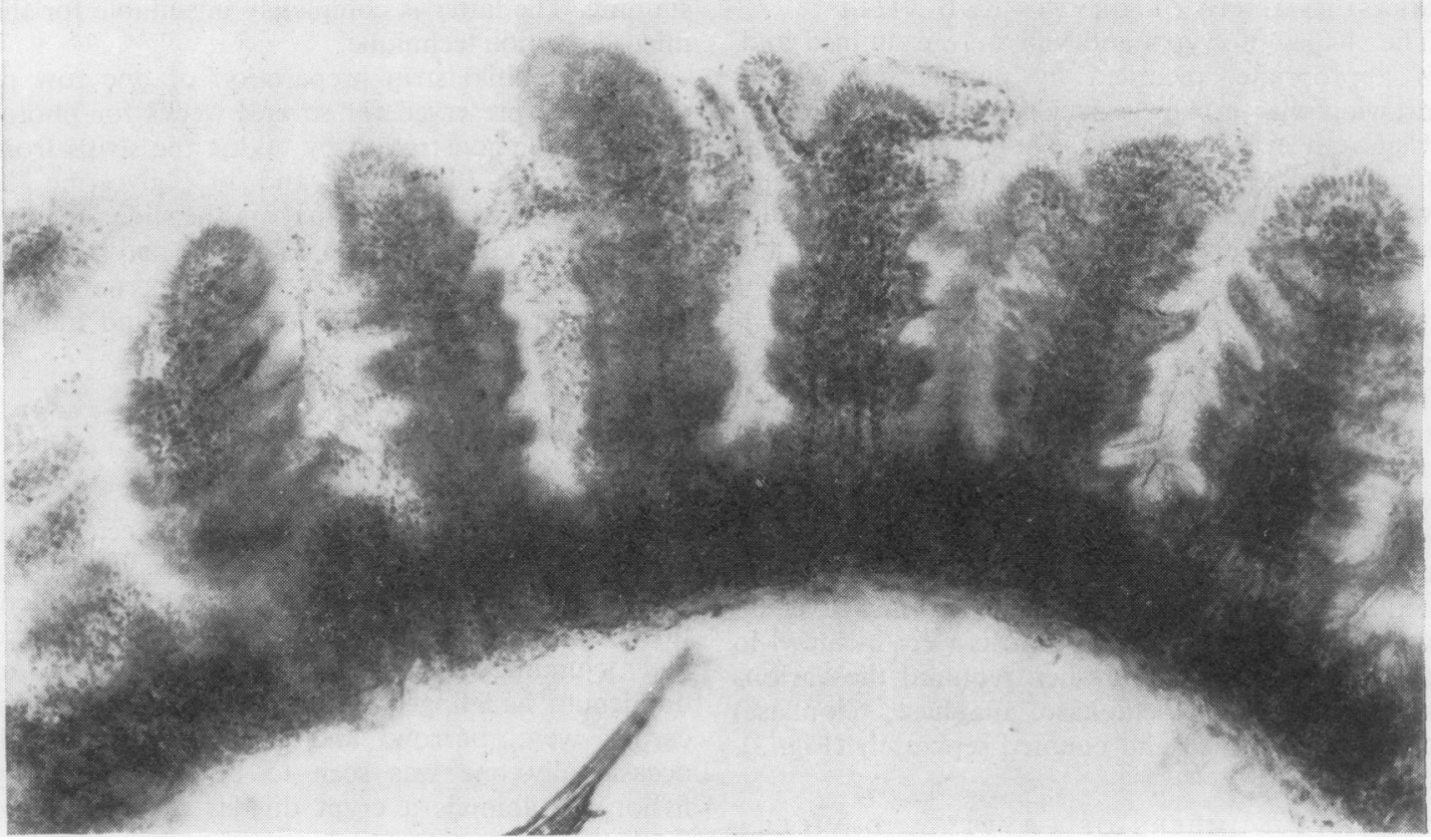

Fig. 1 Strip of small intestine with several finger villi and short crypts $(S c h i f f \times 75)$.

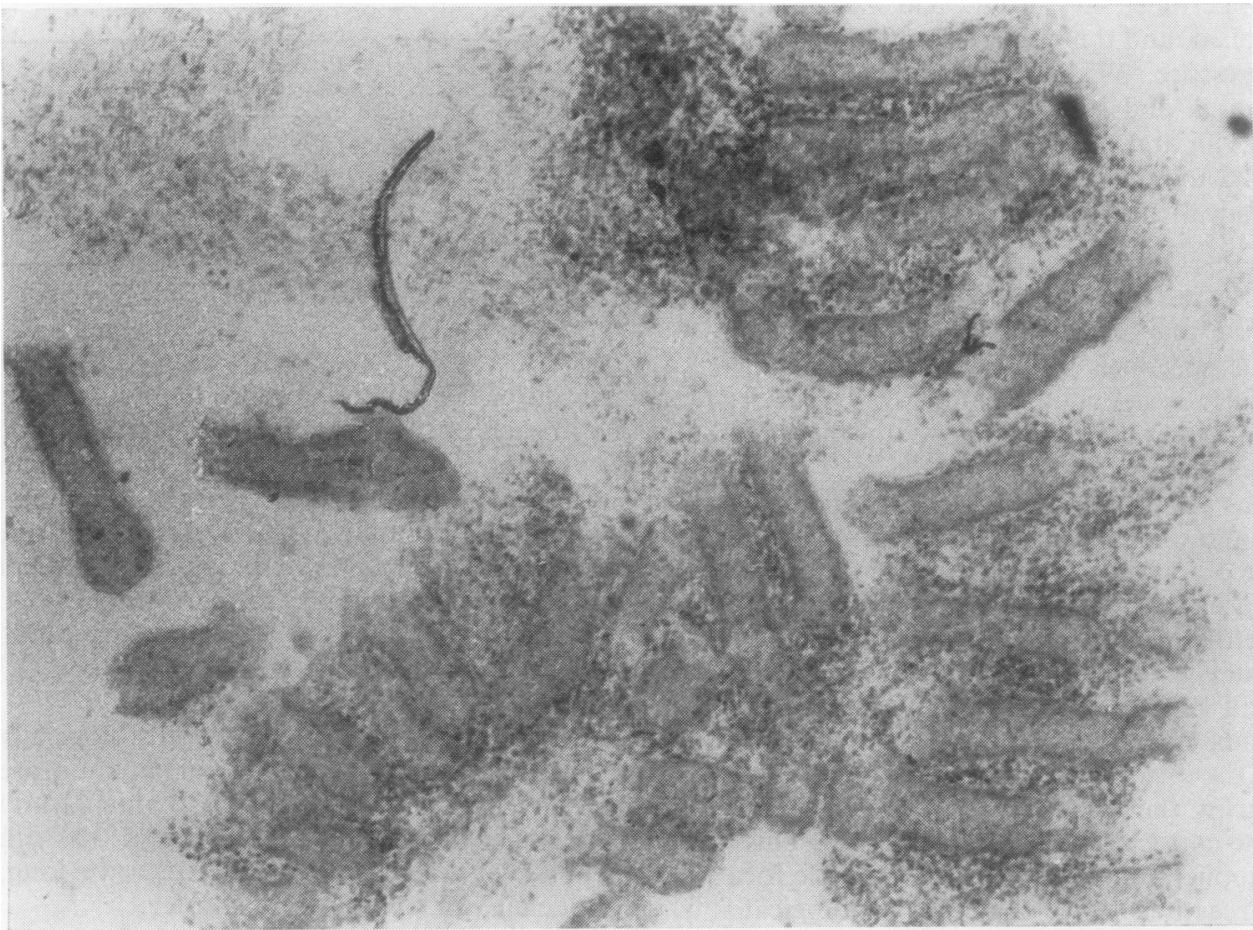

crypts of Liebs erkuhnliberated intestingby gentle pres. slip (Schiff $\times$

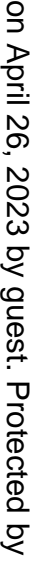




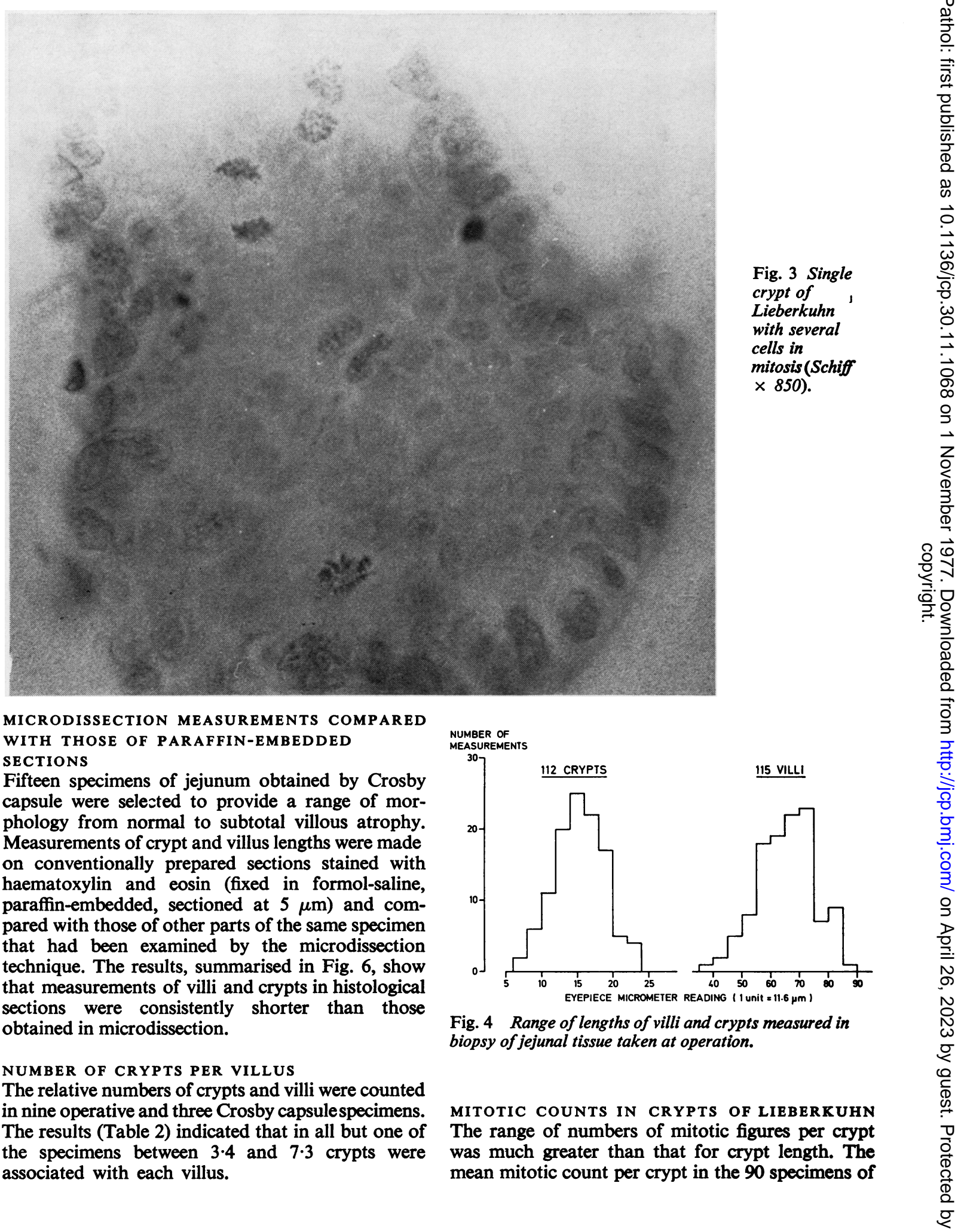



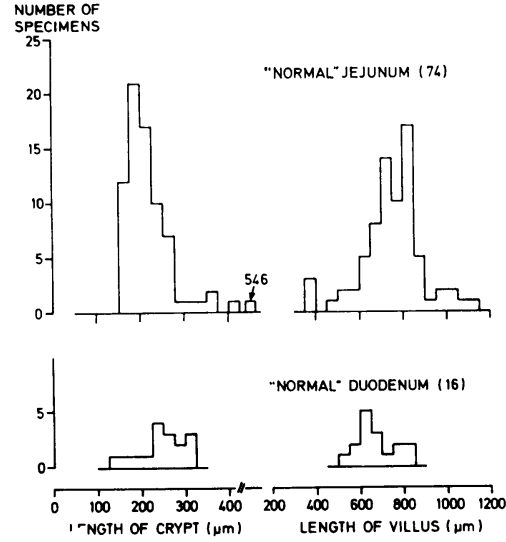

Fig. $5 \quad \mid \quad$ and crypt lengths in 90 biopsies of histologically wurmal specimens from duodenum or jejunum.

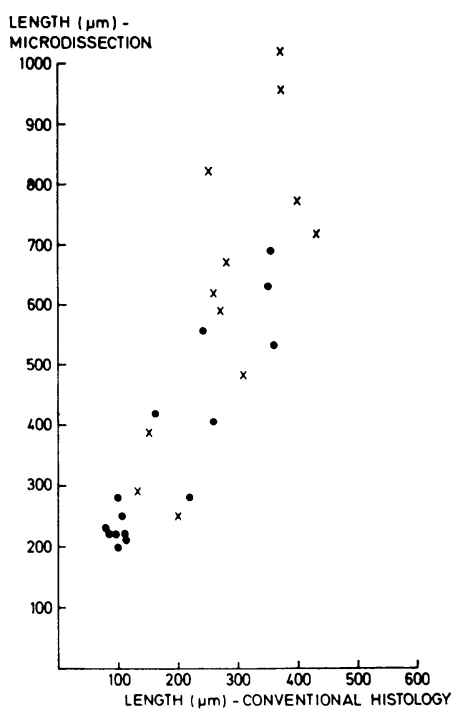

Fig. 6 Measurements of crypts $(\bullet)$ and villi $(x)$ in specimens examined by conventional histology and by microdissection.

Table 2 Relative numbers of crypts and villi in biopsies of jejunum

\begin{tabular}{ll}
\hline Specimen & No. of crypts per villus \\
\hline Jejunum (operative) & $3 \cdot 4,4 \cdot 1,4 \cdot 4.5 \cdot 6,6.1$, \\
& $6 \cdot 1,6 \cdot 5,15 \cdot 4$ \\
Ileum (operative) & $8 \cdot 5$ \\
Jejunum (Crosby capsule) & $3 \cdot 4,4 \cdot 5,7 \cdot 3$ \\
\hline
\end{tabular}

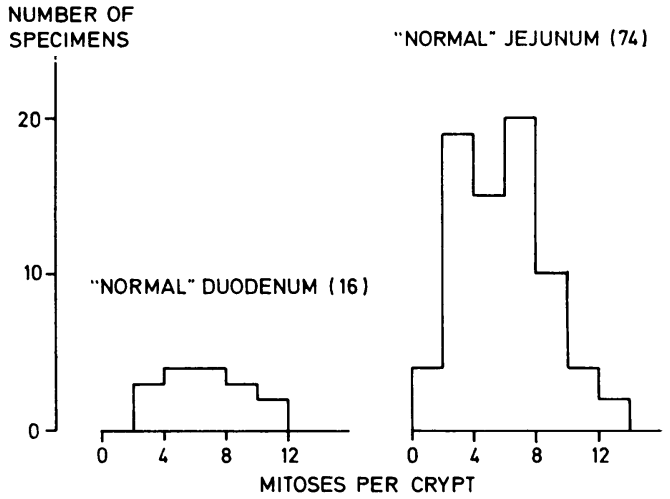

Fig. 7 Number of mitoses per crypt in 90 histologically normal specimens from duodenum or jejunum.

small intestine is shown in Fig. 7. In most specimens there were between 1 and 12 mitoses per crypt.

STAGES OF MITOSIS IN CRYPTS

Counts of the cells at different stages of mitosis were made in one specimen of histologically normal jejunum and in a specimen of duodenum from a patient with untreated coeliac disease. The results, summarised in Table 3, showed that most cells were in prophase or telophase.

\section{Conclusions}

This technique is simple and rapid and can be applied to fragments of tissue obtained for diagnostic biopsy. Microdissection methods give accurate information and insight into the sizes and shapes of villi and crypts and supplement dissecting microscopy. Since the technique also allows the mitotic activity of single crypts to be measured it should be appropriate for investigating epithelial cell kinetics in diseases in which crypt hyperplasia or hypoplasia are expected.

From our examination of 90 specimens of small intestine we propose the following be taken as normal adult values: villus length $>500 \mu \mathrm{m}$; crypt length 150-300 $\mu \mathrm{m}$; crypt mitoses 1-12 mitotic figures per crypt.

We thank the clinical investigation nurses of the Gastro-Intestinal Unit who obtained the Crosby capsule specimens and also of our medical and surgical colleagues who collected specimens at endoscopy or laparotomy. This work was supported by grants from the Medical Research Council and the Camilla Samuel Fund. 
Table 3 Stages of mitosis in crypts of Lieberkuhn

\begin{tabular}{lcccccc}
\hline Nature of specimen & $\begin{array}{l}\text { No. of crypts } \\
\text { examined }\end{array}$ & $\begin{array}{l}\text { Total No. of } \\
\text { mitoses }\end{array}$ & \multicolumn{2}{l}{ Stages of mitosis: } & & \\
\cline { 5 - 7 } & 12 & 76 & Prophase & Metaphase & Anaphase & Telophase \\
\hline $\begin{array}{l}\text { Normal jejunum } \\
\begin{array}{l}\text { Duodenum (untreated coeliac } \\
\text { disease) }\end{array}\end{array}$ & 9 & 480 & 184 & 5 & 2 & 37 \\
\hline
\end{tabular}

\section{References}

Cairnie, A. B., and Millen, B. H. (1975). Fission of crypts in the small intestine of the irradiated mouse. Cell and Tissue Kinetics, 8, 189-196.

Clarke, R. M. (1970). Mucosal architecture and epithelial cell production rate in the small intestine of the albino rat. Journal of Anatomy, 107, 519-529.

Clarke, R. M. (1972). The effect of growth and of fasting on the number of villi and crypts in the small intestine of the albino rat. Journal of Anatomy, 112, 27-33.

Clarke, R. M. (1973). Progress in measuring epithelial turnover in the villus of the small intestine. Digestion, 8, 161-175.

Clarke, R. M. (1974). Control of intestinal epithelial replacement: lack of evidence for a tissue-specific blood-borne factor. Cell and Tissue Kinetics, 7, 241-250.

Clarke, R. M. (1975a). Diet, mucosal architecture and epithelial cell production in the small intestine of specified-pathogen-free and conventional rats. Laboratory Animals, 9, 201-209.
Clarke, R. M. (1975b). The time-course of changes in mucosal architecture and epithelial cell production and cell shedding in the small intestine of the rat fed after fasting. Journal of Anatomy, 120, 321-327.

Clarke, R. M. (1976). Evidence for both luminal and systemic factors in the control of rat intestinal epithelial replacement. Clinical Science and Molecular Medicine, 50, 139-144.

Clarke, R. M., Ecknauer, R., and Feyerabend, G. (1976). Analysis of the effects of food and of digestive secretions on the small intestine of the rat. I. Mucosal morphology and epithelial replacement. Gut, 17, 895-899.

MacDonald, T. T., and Ferguson, A. (1977). Hypersensitivity reactions in the small intestine. 3 . The effects of allograft rejection and of graft-versus-host disease on epithelial cell kinetics. Cell and Tissue Kinetics, 10, 301-312.

Wimber, D. R., and Lamerton, L. F. (1963). Cell population studies on the intestine of continuous irradiated rats. Radiation Research, 18, 137-146. 